\title{
Study of the Effect of Bending Deformation on the Performance of Flexible Polymer Layered Humidity Sensor ${ }^{+}$
}

\author{
Katerina Lazarova $^{1, *}$, Silvia Bozhilova ${ }^{2}$, Sijka Ivanova ${ }^{2}$, Darinka Christova ${ }^{2}$ (D) and Tsvetanka Babeva ${ }^{1, *}$ (D) \\ 1 Institute of Optical Materials and Technologies "Acad. J. Malinowski", Bulgarian Academy of Sciences, \\ Akad. G. Bonchev str., bl. 109, 1113 Sofia, Bulgaria \\ 2 Institute of Polymers, Bulgarian Academy of Sciences, Akad. G. Bonchev Str., bl. 103-A, 1113 Sofia, Bulgaria; \\ s.bozhilova@polymer.bas.bg (S.B.); sivanova@polymer.bas.bg (S.I.); dchristo@polymer.bas.bg (D.C.) \\ * Correspondence: klazarova@iomt.bas.bg (K.L.); babeva@iomt.bas.bg (T.B.); Tel.: +359-02-979-3521 (K.L.) \\ + Presented at the 8th International Symposium on Sensor Science, 17-28 May 2021; Available online: \\ https://i3s2021dresden.sciforum.net/.
}

check for updates

Citation: Lazarova, K.; Bozhilova, S.; Ivanova, S.; Christova, D.; Babeva, T. Study of the Effect of Bending Deformation on the Performance of Flexible Polymer Layered Humidity Sensor. Eng. Proc. 2021, 6, 6. https:// doi.org/10.3390/I3S2021Dresden10069

Academic Editors: Gianaurelio Cuniberti and Larysa Baraban

Published: 17 May 2021

Publisher's Note: MDPI stays neutral with regard to jurisdictional claims in published maps and institutional affiliations.

Copyright: (C) 2021 by the authors. Licensee MDPI, Basel, Switzerland. This article is an open access article distributed under the terms and conditions of the Creative Commons Attribution (CC BY) license (https:// creativecommons.org/licenses/by/ $4.0 /)$.

\begin{abstract}
Humidity-sensitive polymer, namely poly(vinyl alcohol-co-vinyl acetal), was deposited on a flexible poly(ethylene terephthalate) (PET) substrate pre-covered with a sputtered Au:Pd thin layer in order to develop an optical flexible humidity sensor. The spin-coating method was applied for the thin polymer film deposition. The optical and sensing properties of the device were studied after repeated bending deformation in the range of 25-1000 times. Transmittance measurements at different levels of relative humidity were conducted in order to examine the sensing properties of the probed flexible sample. The influence of the number of bending deformations on the performance of the sensor is studied, and the possibility for its successful application is demonstrated and discussed.
\end{abstract}

Keywords: humidity; optical sensor; polymers; flexible substrates; PET; thin films

\section{Introduction}

Various types of materials have been considerably studied in order to develop humidity sensors with high sensitivity and stability, broad operating humidity range, and prompt response time. However, the requirement of a low-cost humidity sensor with high performance is hard to achieve, and its development faces multiple challenges such as compatible materials and substrates, suitable manufacturing techniques, etc. A variety of materials can be used [1-3], but polymers stand out due to their easy deposition in the form of thin films, relatively low cost, tailored functionality, and fast response [4].

In this study, we use a modified PVA copolymer with acetal content $24 \%$ (PVAAc24) $[5,6]$ spin-coated on a poly(ethylene terephthalate) (PET) substrate pre-covered with a sputtered $30 \mathrm{~nm}$ thick Au:Pd layer. The influence of the number of bending deformations (range 25-1000) on the performance of the sensor and on the optical characteristics was investigated.

\section{Materials and Methods}

Hydrophobically modified PVA copolymer, namely PVA-Ac24, was synthesized by partial acetalization of hydroxyl groups of PVA with acetaldehyde as already described in [5-8]. PET flexible substrate and borosilicate glass were pre-covered with Au:Pd sublayer of gold/palladium, ratio of 80:20 and thickness of $30 \mathrm{~nm}$. Thin metal films were deposited on all substrates by cathode sputtering of gold/palladium target (Quorum Technologies, Lewes, UK) for $60 \mathrm{~s}$ under vacuum $4 \times 10^{-2} \mathrm{mbar}$ by using Mini Sputter Coater SC7620 system (Quorum Technologies, Lewes, UK). Thin copolymer film was deposited on silicon wafer and on PET substrate with metal sublayer via spin-coating method. Samples were annealed in air for $30 \mathrm{~min}$ at $60^{\circ} \mathrm{C}$ afterwards. Surface roughness and quality of the flexible sample was monitored by 3D Optical Profiler (Zeta-20, Zeta Instruments, USA) before 
and after bending deformations. Sensing properties of the sensor for each set of bending deformations were studied by measuring transmittance values $\mathrm{T}$ in humidity range from 5 to $95 \% \mathrm{RH}$ at fixed wavelength that is preliminarily chosen as the wavelength of the highest humidity responses $\Delta \mathrm{T}_{\max }=\left|\mathrm{T}_{5 \mathrm{RH}}-\mathrm{T}_{95 \mathrm{RH}}\right|$.

\section{Results and Discussion}

The examination of the surface of the sample after each bending deformation set showed no change in the quality of the film in contrast to the measured transmittance spectra: the transmittance coefficient $\mathrm{T}$ increased with the increase in the number of bends [Supplementary Materials, Slide 9]. The transmission coefficient at $600 \mathrm{~nm}$ wavelength after 25 bends was $47.6 \%$ and gradually increased to $49.1 \%$ after 1000 deformations. The possible reason for the observed slight increase in $\mathrm{T}$ is the change of transmittance of the metal overlayer due to small sub-micron cracks created as a result of bending deformations. Generally, the transparency level and transmission coefficients were similar, and there was no deterioration of the optical quality of the films: all samples were transparent in the visible range.

The measured transmittance spectra $\mathrm{T}$ for humidity levels of 5\%, 40\%, and $95 \% \mathrm{RH}$ of the sample after 50 bends are shown in Figure 1. It is seen that for the highest humidity, the spectrum shifts toward higher wavelengths, and transmittance change $\Delta \mathrm{T}_{\max }$ at the wavelength of $500 \mathrm{~nm}$ is $8 \%$. Similar values of $\Delta \mathrm{T}$ around $7 \pm 1 \%$ are measured after each set of bending deformations for the flexible PET sensor [Supplementary materials, Slide 11]. When the polymer film is exposed to higher humidity levels, its thickness increases, and its refractive index decreases. As a result, a change in transmittance spectra is observed. It is interesting to note that there is no decrease of polymer swelling with increasing the number of bending deformations up to 1000 . Moreover, the exposure to humidity of the bare PET substrate does not lead to any change of transmittance spectra, which means that the measured $\Delta \mathrm{T}$ is a consequence of humidity-induced changes in the polymer film only.

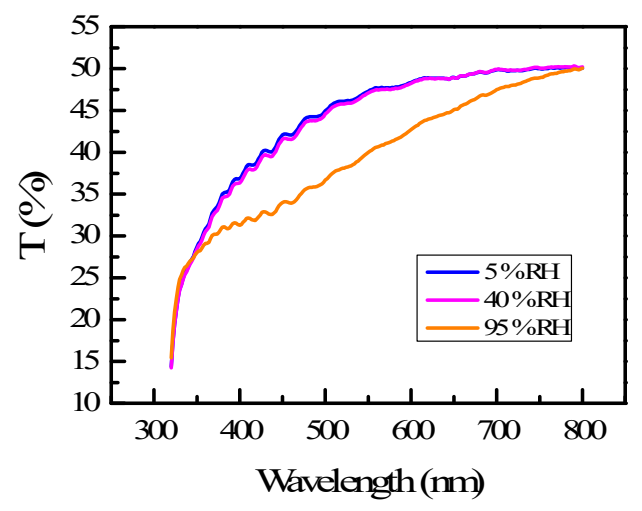

Figure 1. Transmittance spectra of the flexible polymer humidity sensor after 50 bending deformations for relative humidity levels of $5 \%, 40 \%$, and $95 \% \mathrm{RH}$.

\section{Conclusions}

A humidity-sensitive system of a flexible PET substrate and a poly(vinyl alcohol-covinyl acetal) thin film with an intermediate metal layer has been successfully developed. A change in the transmission spectrum after exposure to different relative humidity levels in the whole range from 5 to $95 \% \mathrm{RH}$ was observed. A series of deformation bends from 25 to 1000 led to a shift of the transmission spectrum of the sensor to higher values. The measured change $\Delta \mathrm{T}$ after each set of bends was about $7 \%$ and was independent of the number of bending deformations up to 1000 .

Supplementary Materials: The following are available online at https://www.mdpi.com/article/10 .3390/I3S2021Dresden-10069/s1, Poster S1: i3s_S6_10069_Study_of_the_effect_of_bending_slides. 
Author Contributions: Conceptualization, T.B., D.C. and K.L.; methodology, T.B., D.C. and K.L.; software, T.B. and K.L.; validation, T.B., D.C. and K.L.; formal analysis, S.B., S.I. and K.L.; investigation, K.L. and S.B.; resources, D.C. and T.B.; data curation, K.L., D.C. and T.B.; writing-original draft preparation, K.L.; writing-review and editing, T.B., D.C. and K.L.; visualization, T.B. and K.L.; supervision, T.B. and D.C.; project administration, T.B. and K.L. All authors have read and agreed to the published version of the manuscript.

Funding: This research received no external funding.

Acknowledgments: K. Lazarova and S. Bozhilova acknowledge the National Scientific Program for young scientists and postdoctoral fellows, funded by the Bulgarian Ministry of Education and Science (MES) with DCM 577/2018 and 271/2019. Research equipment from the Distributed Research Infrastructure INFRAMAT, part of the Bulgarian National Roadmap for Research Infrastructures, supported by the Bulgarian Ministry of Education and Science, was used in this investigation.

Conflicts of Interest: The authors declare no conflict of interest.

\section{References}

1. Zhang, J.; Zhong, J.; Fang, Y.; Wang, J.; Huang, G.; Cui, X.; Mei, Y. Roll up polymer/oxide/polymer nanomembranes as a hybrid optical microcavity for humidity sensing. Nanoscale 2014, 6, 13646-13650. [CrossRef]

2. Naydenova, I.; Jallapuram, R.; Toal, V.; Martin, S. A visual indication of environmental humidity using a color changing hologram recorded in a self-developing photopolymer. Appl. Phys. Lett. 2008, 92, 031109. [CrossRef]

3. Naydenova, I.; Grand, J.; Mikulchyk, T.; Martin, S.; Toal, V.; Georgieva, V.; Thomas, S.; Mintova, S. Hybrid Sensors Fabricated by Inkjet Printing and Holographic Patterning. Chem. Mater. 2015, 27, 6097-6101. [CrossRef]

4. Wei, M.; Gao, Y.; Li, X.; Serpe, M.J. Stimuli responsive polymers and their applications. Polym. Chem. 2017, 8, 127-143. [CrossRef]

5. Christova, D.; Ivanova, S.; Ivanova, G. Water-soluble temperature-responsive poly(viny1 alcohol-co-vinyl acetal)s. Polym. Bull. 2003, 50, 367-372. [CrossRef]

6. Lazarova, K.; Bozhilova, S.; Novakov, C.; Christova, D.; Babeva, T. Amphiphilic Poly(vinyl Alcohol) Copolymers Designed for Optical Sensor Applications-Synthesis and Properties. Coatings 2020, 10, 460. [CrossRef]

7. Lazarova, K.; Bozhilova, S.; Ivanova, S.; Christova, D.; Babeva, T. Moisture-responsive polymer films on flexible substrates for optical sensing of humidity. Eng. Proc. 2020, 2, 19.

8. Lazarova, K.; Bozhilova, S.; Christova, D.; Babeva, T. Poly(vinyl alcohol)-based thin films for optical humidity sensing. J. Phys. Conf. Ser. 2020, 1492. [CrossRef] 